\title{
Retrospective evaluation of landslide susceptibility maps and review of validation practice
}

\author{
Paul Fleuchaus $^{1} \cdot$ Philipp Blum $^{1} \cdot$ Martina Wilde $^{2} \cdot$ Birgit Terhorst $^{2} \cdot$ Christoph Butscher $^{3}$ (i)
}

Received: 15 January 2021 / Accepted: 29 April 2021 / Published online: 21 July 2021

(c) The Author(s) 2021

\begin{abstract}
Despite the widespread application of landslide susceptibility analyses, there is hardly any information about whether or not the occurrence of recent landslide events was correctly predicted by the relevant susceptibility maps. Hence, the objective of this study is to evaluate four landslide susceptibility maps retrospectively in a landslide-prone area of the Swabian Alb (Germany). The predictive performance of each susceptibility map is evaluated based on a landslide event triggered by heavy rainfalls in the year 2013. The retrospective evaluation revealed significant variations in the predictive accuracy of the analyzed studies. Both completely erroneous as well as very precise predictions were observed. These differences are less attributed to the applied statistical method and more to the quality and comprehensiveness of the used input data. Furthermore, a literature review of 50 peer-reviewed articles showed that most landslide susceptibility analyses achieve very high validation scores. $73 \%$ of the analyzed studies achieved an area under curve (AUC) value of at least $80 \%$. These high validation scores, however, do not reflect the high uncertainty in statistical susceptibility analysis. Thus, the quality assessment of landslide susceptibility maps should not only comprise an index-based, quantitative validation, but also an additional qualitative plausibility check considering local geomorphological characteristics and local landslide mechanisms. Finally, the proposed retrospective evaluation approach cannot only help to assess the quality of susceptibility maps and demonstrate the reliability of such statistical methods, but also identify issues that will enable the susceptibility maps to be improved in the future.
\end{abstract}

Keywords Landslides $\cdot$ Hazard maps $\cdot$ Predictive performance $\cdot$ Review $\cdot$ Swabian Alb

\section{Introduction}

The overriding goal of this study is to provide a positive impulse for quality assessment of landslide susceptibility analysis by focusing not only on the calculation, but also on the evaluation process. We want to illustrate that the validation procedure of landslide susceptibility maps is not a burdensome obligation, but a chance to increase the reliability, transparency and-last but not least - the acceptance of such

Christoph Butscher

christoph.butscher@ifgt.tu-freiberg.de

1 Institute of Applied Geosciences (AGW), Karlsruhe Institute of Technology (KIT), Kaiserstr. 12, 76131 Karlsruhe, Germany

2 Institute of Geography and Geology, University of Wurzburg, Am Hubland, 97074 Würzburg, Germany

3 Technische Universität Bergakademie Freiberg, Geotechnical Institute, Gustav-Zeuner-Str. 1, 09599 Freiberg, Germany maps. We had the concern that quantitative validation scores of landslide susceptibility maps may in certain cases obscure the predictive accuracy. Therefore, the study aimed particularly at evaluating the predictive performance of landslide susceptibility maps retrospectively, and relating the results to validation practice.

Worldwide, 300 million people and an area of 3.7 million $\mathrm{km}^{2}$ are prone to landslides (Dilley et al. 2005). 2620 fatal landslides occurred in the period from 2004 to 2010, claiming 32,322 victims (Petley 2012). The annual global damage from landslides is estimated at 18 billion euros (Haque et al. 2016). In Europe, 476 deadly landslides claimed a total of 1370 fatalities in the period from 1995 to 2014. The average annual damage is estimated at 4.7 billion euros in Europe (Haque et al. 2016) and 221 million euros in Germany (Klose et al. 2016). It is expected that the number of fatal landslides will further increase. The reasons discussed are thawing of permafrost (Gruber and Haeberli 2007; Etzelmüller and Frauenfelder 2009), the increasing number 
of heavy-rainfall events (Crozier 2010; Jakob and Lambert 2009), population growth, and a change in land use (Glade 2003; Huppert and Sparks 2006; Petley 2010; Petley et al. 2007; Promper et al. 2014).

Developing countries are particularly affected by landslides, especially in Asia and Central and South America (Petley 2012). Here, the frequent occurrence of severe landslide events due to detrimental geo-environmental settings coincides with insufficient landslide mitigation strategies (Eder et al. 2009; Anderson et al. 2011). An efficient landslide risk management is often impeded by various challenges to local authorities, such as limited financial means or regions which are difficult to access (e.g., Rozos et al. 2011). At the same time, the development of powerful Geographic Information Systems (GIS), an ever-increasing resolution of remote sensing data as well as increasing computing power open new perspectives in landslide predictions. In this context, statistical methods moved increasingly into the scientific focus to analyze landslide susceptibility, especially in landslide-prone areas in developing countries (e.g., Bousta and Ait Brahim 2018; Lee et al. 2018; Nsengiyumva et al. 2018; Awawdeh et al. 2018; Tasoglu et al. 2016). Statistical methods are applicable on a regional or even national scale with comparably low financial, temporal, and personal expenses (e.g., Yesilnacar and Topal 2005). Thus, the number of statistical landslide susceptibility investigations continuously increased during recent years (Reichenbach et al. 2018). However, statistical analyses of landslide risks still attract little attention from authorities and regulators (Petschko et al. 2014). This can be explained by the sophisticated calculation processes, and also by the fact that susceptibility maps can be responsible for restrictions during planning processes.

To build up trust in statistical landslide analyses, it is crucial to demonstrate the quality of the final susceptibility map by a transparent validation. The standard evaluation approach is to analyze the agreement between the resulting map and observed data (Corominas et al. 2014). The observed data comprises the absence or presence of landslides in the investigation area of an independent test sample (Frattini et al. 2010). The most frequently applied validation techniques are cutoff independent methods such as ReceiverOperating Characteristics (ROC) or Prediction Rate Curves (PRC) and Success Rate Curves (SRC) (Corominas et al. 2014; Frattini et al. 2010; Reichenbach et al. 2018). Despite the widespread application, several authors question the reliability and accuracy of the standard validation practice in statistical landslide prediction. According to Bell (2007), Brenning (2005), and Reichenbach et al. (2018), several authors evaluate the predictive performance of the model only based on a training dataset. However, this gives only information about the goodness of fit of the model, and not on the actual predictive performance of future landslide occurrence. Kalantar et al. (2017) further state that the way of partitioning the landslide inventory into test and training datasets highly influences the prediction results. According to Bell (2007), temporal partition can lead to inaccuracies in the case of a homogeneous investigation area. The same applies to landslide reactivations in the case of a spatial partitioning. Steger et al. (2016a, b) concluded that the validation of a susceptibility map is also highly influenced by a bias in the landslide inventory. The result is that geomorphologically implausible landslide susceptibility maps can achieve very high validation scores (Steger et al. 2017). According to Neuhäuser and Terhorst (2007), Corominas et al. (2014), Guzzetti (2006), and Reichenbach et al. (2018), the most reliable way to assess the predictive performance of a landslide susceptibility map is to evaluate the predictive power retrospectively. This means that the predictive performance is validated based on a landslide event that occurred after making the map. Since the evidence of the validity has to be supplied together with the final map, this retrospective approach is only applicable in addition to the standard evaluation approach after a sufficient number of landslides has occurred after the creation of the map. However, compared to the standard validation approach proposed by Chung and Fabbri (2003), the retrospective evaluation is characterized by a higher level of objectivity, accuracy and comprehensibility.

To the best of our knowledge, no attempt has been made so far to assess the quality of statistical landslide susceptibility maps retrospectively. The objective of this study is, therefore, to demonstrate this validation approach in a landslide-prone area in South Germany called the Swabian Alb. The study is carried out by evaluating the predictive performance of four different landslide susceptibility maps, published before the year 2013, against an event with several landslides which occurred in 2013. The performance of each map is qualitatively analyzed and differences in the predictive accuracy are evaluated. The results are discussed with respect to the current validation practice applied to 50 recent landslide susceptibility investigations. Finally, we suggest measures to further increase the reliability of and reliance on statistical landslide investigations.

\section{Study area}

The study area is located south-east of the city of Tübingen at the foot of the Jurassic escarpment of the Swabian Alb, a low mountain range in South West Germany (Fig. 1). Different types of mass movements are widespread across this region and were the subject of numerous investigations (Schädel and Stober 1988; Dongus 1977; Bibus 1999; Terhorst 1997, 2001; Kraut 1999; Bell 2007; Kreja and Terhorst 2005; Terhorst and Kreja 2009; Thiebes 2011). The total 


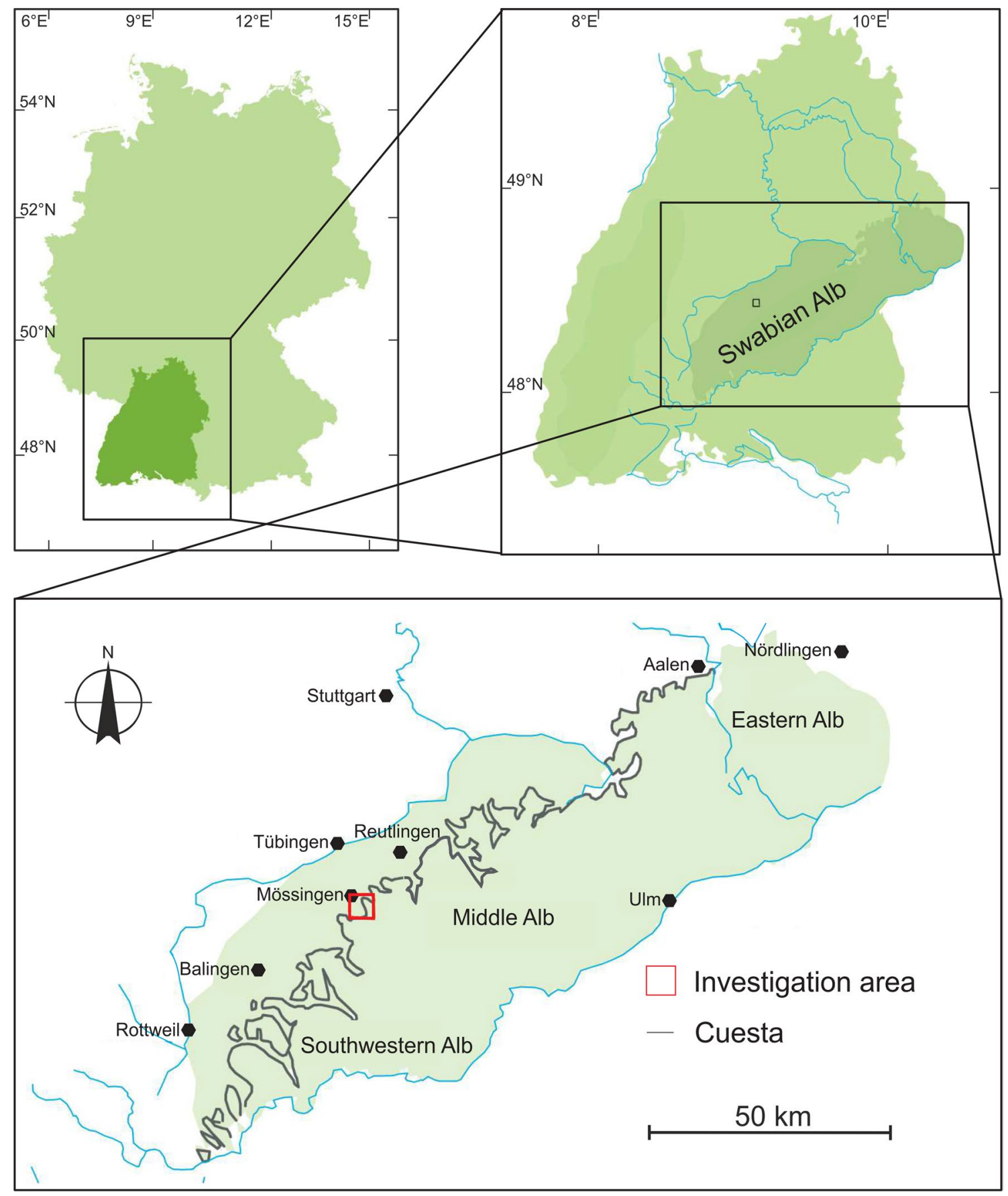

Fig. 1 Location of the study area at the Jurassic cuesta escarpment of the Middle Swabian Alb

number of landslides is estimated to be 30,000 for the entire Swabian Alb (Bell 2007). With an affected area of $0.6 \mathrm{~km}^{2}$, the most famous and best-documented landslide occurred in Mössingen in 1983 (Terhorst 2001; Schädel and Stober 1988).

Even though landslides are a danger, several residential areas were developed at the landslide-prone foot of the Swabian Alb escarpment (Terhorst and Kreja 2009; Blöchl and Braun 2005), and therefore, there has been damage to property (Kreja and Terhorst 2005; Sass et al. 2008). The area of Mössingen-Öschingen, a town located in the Middle Swabian Alb south of the city of Tübingen is particularly affected. To identify vulnerable residential areas, several authors have analyzed landslide susceptibility in this area (Thein 2000; Bell 2007; Neuhäuser and Terhorst 2007,2009; Terhorst and Kreja 2009). Figure 2 illustrates the study area 


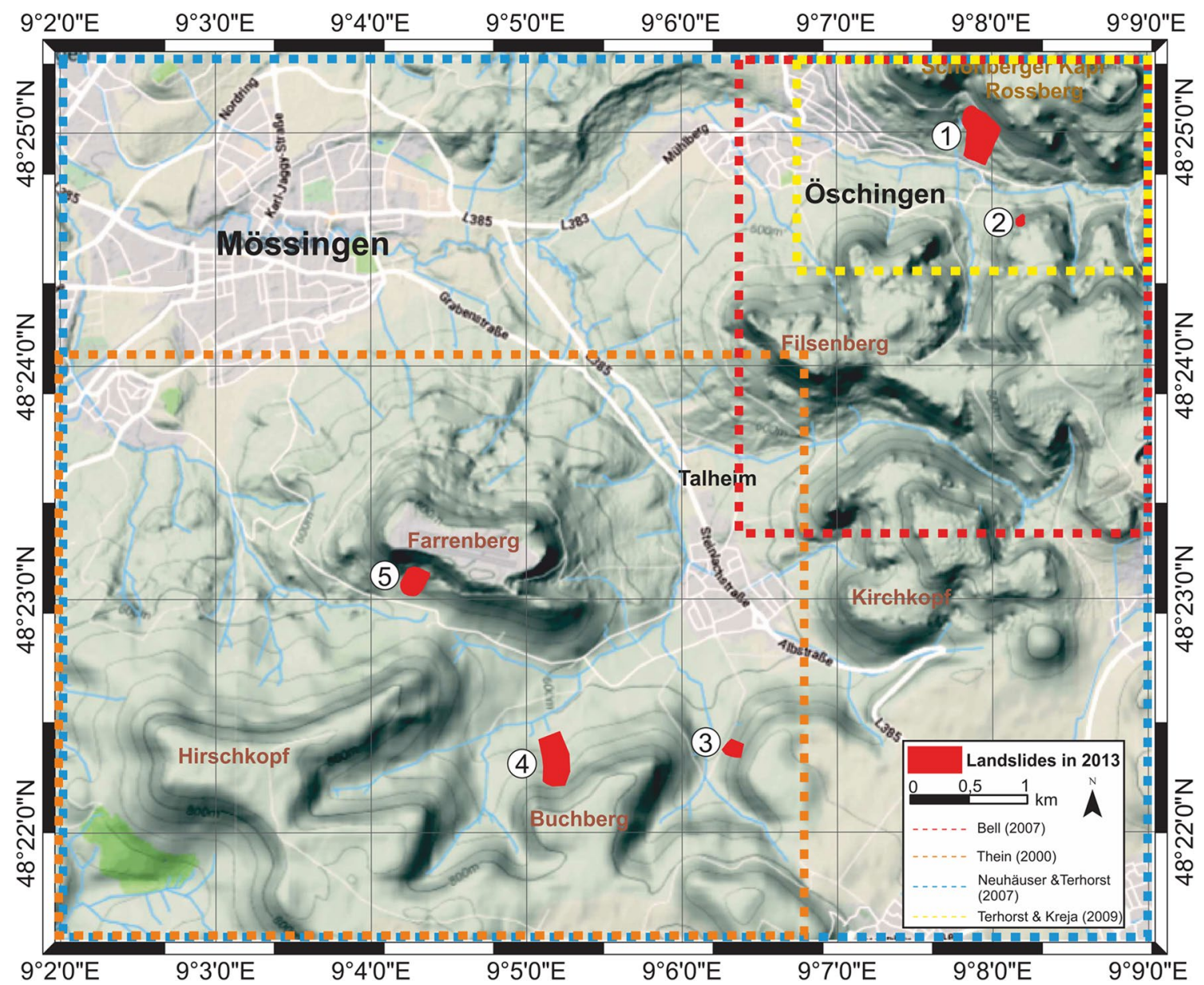

Fig. 2 Study area Mössingen-Öschingen in the Middle Swabian Alb. Past susceptibility studies are marked by the dotted lines, landslides triggered by the 2013 heavy-rainfall event are highlighted in red (base map from Google Maps, 2017)

of Mössingen-Öschingen as well as the extent of past landslide susceptibility studies. These studies differ in terms of the applied method, the size of the area, and the kind and resolution of the input data (Table 1).

In June 2013, a period of long-lasting heavy rainfalls triggered about 20 landslides along the slopes of the Middle Swabian Alb. Using aerial photographs, field trips and newspaper articles, 5 landslides have been identified in the investigation area of Mössingen-Öschingen (Figs. 2, 3b-d). One landslide hit the "Landhaussiedlung", a residential area with 30 houses built in the 1960s (Fig. 3d); where three houses had to be demolished after the event (Fig. 3c) with a total damage estimated at several million euros. The largest landslide occurred in the south of the study area (Buchberg, Nr. 4 in Figs. 2, 3b). Although, in this case, no residential area was affected, the estimated loss of mainly agricultural land was estimated at about 100,000 euros (LGL 2014). The previous landslide susceptibility investigations in the study area were performed prior to the landslide event in 2013. Hence, this event can

Table 1 Landslide susceptibility studies in the area of Mössingen-Öschingen in the Middle Swabian Alb

\begin{tabular}{|c|c|c|c|}
\hline & Method & Investigation scale & Input data \\
\hline Bell (2007) & Logistic regression & Regional & $\begin{array}{l}\text { Landslide inventory: landslide mapping by Dongus (1977), anc } \\
\text { forestry landslide inventory. } 12 \text { causative factors }\end{array}$ \\
\hline Neuhäuser and Terhorst (2007) & Weights of evidences & Regional & 20 Holocene landslides and 9 causative factors \\
\hline Thein (2000) & Logistic regression & Local & 10 Holocene landslides and 8 causative factors \\
\hline Terhorst and Kreja (2009) & Stability index mapping & Site-specific & Based on a high-resolution terrain model and hydrological data \\
\hline
\end{tabular}


Fig. 3 a Mössingen landslide of 1983. b Largest landslide in the 2013 heavy-rainfall event located south of the town of Mössingen (Fig. 2: No. 4). c, d 2013 landslide event devastating the Öschingen residential area "Landhaussiedlung" (Fig. 2:

No. 1). Photos: a A. Dieter in Kreja and Terhorst (2009), b, d Klaus Franke, c Paul Fleuchaus
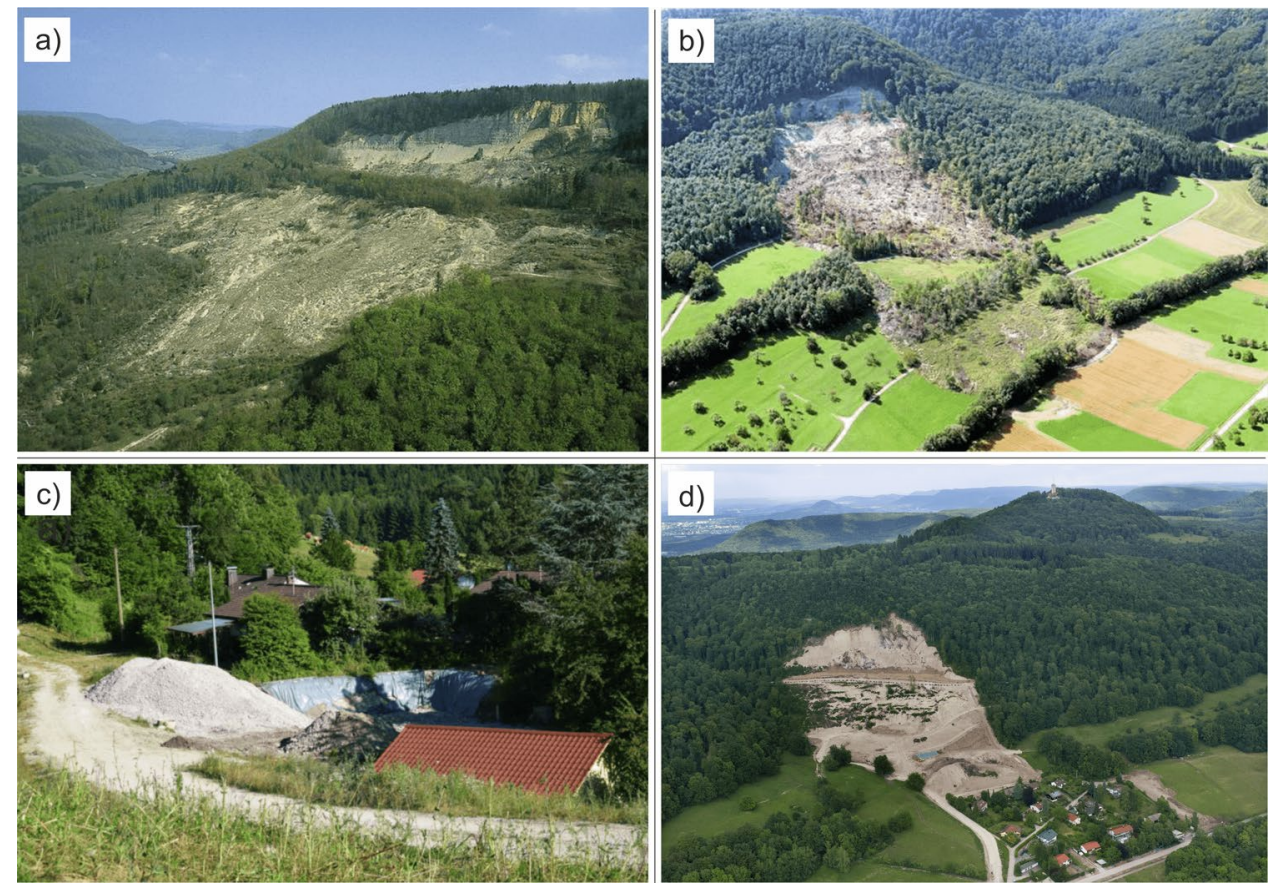

be used to assess the predictive performance of these previous studies retrospectively.

\section{Methodology}

\section{Workflow of establishing landslide susceptibility maps}

Landslide susceptibility represents the identification of areas liable to be affected by landslides, given by a set of geoenvironmental conditions (Guzzetti 2006). The fundamental principle behind landslide susceptibility analyses was initially stated by Brabb (1991): "The past and the present are the key to the future." Hence, future landslides will be more likely to occur under geo-environmental settings associated with past or present slope failures (Guzzetti 2006). To predict future landslide susceptibility, different approaches are used, such as heuristic, deterministic or statistical methods (Soeters and van Westen 1996; Guzzetti et al. 1999; Bell 2007). With a growing availability of high-quality geomorphological data, with increasing processing power and powerful GIS, statistical methods have gained importance and have been the most frequently applied approaches during recent years. Statistical methods are characterized by the ability to investigate large areas with little material effort and relatively low investment in time compared to, for example, extensive site exploration with core drilling and laboratory experiments to calculate the stability of many slopes. Figure 4 illustrates the typical workflow of a statistical landslide analysis.
The initial step in statistical susceptibility investigations is the creation of a landslide inventory containing all past events of the analyzed landslide type (step 1). Second, factor maps are made for all factors affecting landslide susceptibility in the study area (step 2). Both factor maps and landslide inventory must be digitized and integrated into a GIS (step 3), and landslide susceptibility is calculated (step 4). The way of calculating landslide susceptibility depends on the chosen statistical method. In the past, various statistical methods were proposed, reviewed, and discussed by Guzzetti (2006), Bell (2007), van Westen et al. (2003), Carrara (1993), Guzzetti et al. (1999) and Reichenbach et al. (2018).

The reliability of a landslide susceptibility map depends on several factors, such as the quality and completeness of input data, expert knowledge, and investigation scale. Hence, a comprehensive quality assessment in the form of a validation is indispensable. Without this validation, the modeled maps have limited use (Chung and Fabbri 2003; Bell 2007). The cornerstone of most validation approaches is to split the landslide inventory into a training and a test dataset (step 5) (Corominas et al. 2014). The training dataset is used to create the susceptibility map. The test dataset ("unknown" landslides) is used to assess the predictive performance of the created susceptibility map (step 6). The landslide inventory can be split into training and test data based on three criteria: space, time and random partitions (Chung and Fabbri 2003). To assess the validation score, the most frequently used methods are the Receiver-Operating Characteristics (ROC) and the Prediction Rate Curve (PRC) (Corominas et al. 2014; Reichenbach et al. 
Fig. 4 Typical workflow of a statistical landslide analysis (TWI: Topographic Wetting Index; AUC: area under curve)

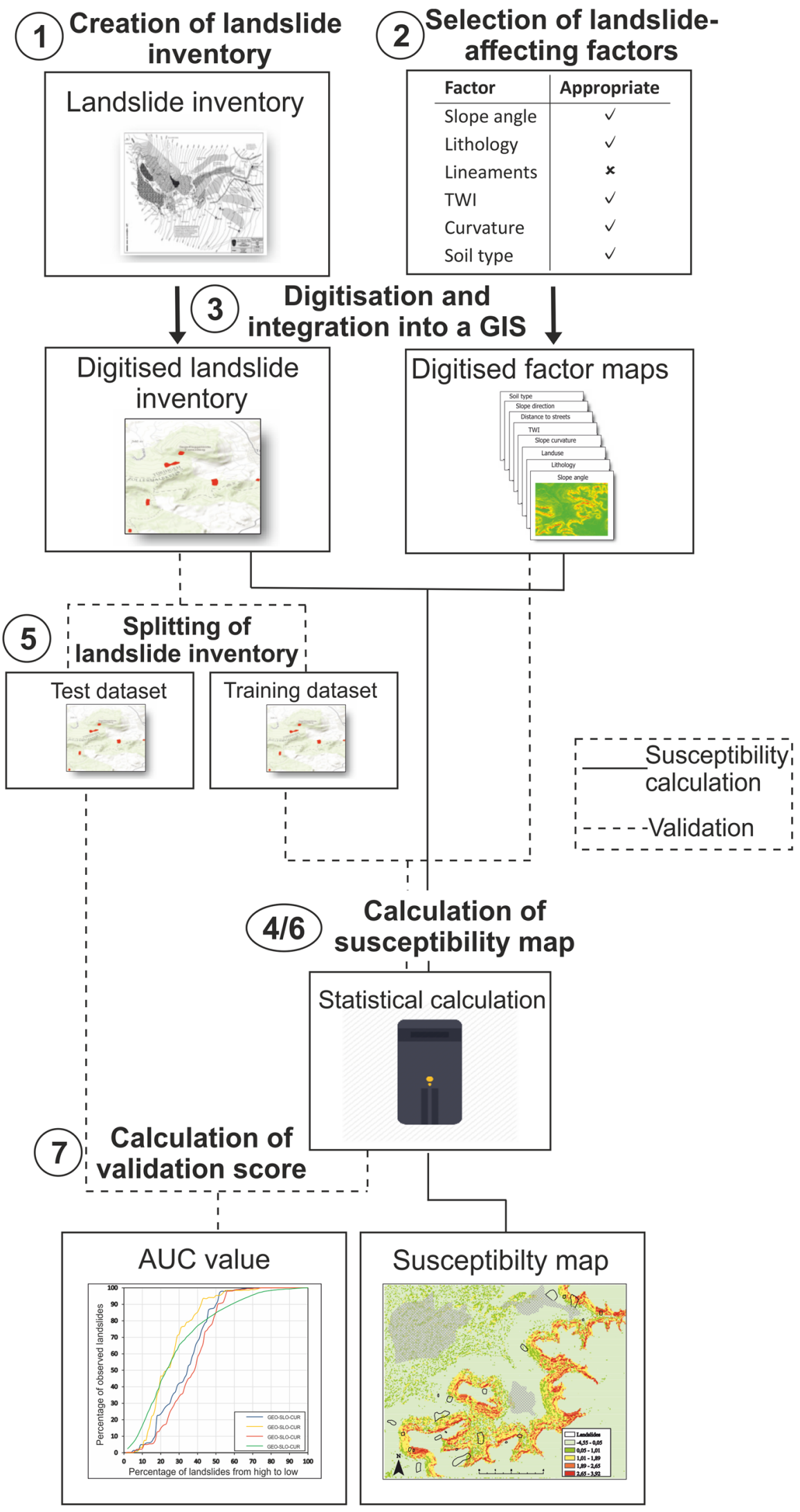


2018). The area under the curve (AUC) can be used as a metric to evaluate the quality of the model.

\section{Retrospective evaluation of landslide susceptibility maps}

Several authors proposed that the easiest and most reliable evaluation strategy is to "wait and see", if the calculated maps predict future landslides correctly or not (Corominas et al. 2014; Neuhäuser and Terhorst 2007; Guzzetti 2006; Reichenbach et al. 2018). However, this idea is usually not feasible, as the validation is requested together with the calculated map. Nevertheless, when considering susceptibility maps published in the past, this "wait and see" strategy is indeed viable, as the "waiting part" is already done. To proceed with the validation ("seeing" part), the only requirement is a set of landslides that occurred after the map was created. These landslides have to assess the predictive performance of the model based on a real dataset. The advantages of a retrospective evaluation compared to the standard practice can be summarized as follows:

- A high level of objectivity, since the retrospective evaluation can be performed by a person other than the producer of the map;

- The landslide inventory used to evaluate the results is independent of the inventory used to calculate the map;

- The landslide inventory used to evaluate the map can be of higher accuracy, as recent landslides can be more precisely mapped than older landslide events;

- The reliability of the map can be demonstrated in a more plausible manner, which helps to gain acceptance of such statistical methods.

This can be done in a qualitative or quantitative manner. A qualitative validation rests on a knowledge-based, subjective judgment by the researcher; for the quantitative approach, susceptibility maps and the landslide polygons can be compared by calculating the precision and sensitivity to evaluate the performance of the maps. Due to the lack of raster information, past susceptibility maps of the area of Mössingen-Öschingen are qualitatively validated in this study. The validation is based on five landslides from the heavy-rainfall event in 2013 (Fig. 2). It is evaluated whether the landslides are located in the zones which were attributed with the highest susceptibility values by the analyzed maps.

\section{Results and interpretation}

\section{Review of validation practice}

According to Reichenbach et al. (2018), more than one-third of all studies did not perform a validation. However, with the study by Chung and Fabbri (2003), the share of properly validated studies gradually increased (Bell 2007; Guzzetti 2006). Figure 5 overviews AUC values of 50 randomly sampled recent statistical landslide investigations as well as the applied statistical method. There is no correlation between the validation score and the statistical method applied. This confirms findings from previous studies that the predictive performance depends rather on the quality of the input data than on the used method (Steger et al. 2016a, b, 2017; Petschko et al. 2014).

At the same time, most studies (73\%) achieved an AUC value of at least $80 \%$. Poor validation scores of less than $70 \%$ were not observed. Thus, either statistical methods consistently predict landslide occurrence very accurately, or ROC and PRC do not reflect the actual predictive performance correctly in all cases. Considering the impact of inaccurate input data, lacking expert knowledge or the over- and underestimation of causative factors, more attention should be paid to the fact that not only the creation of the landslide susceptibility map, but also the validation itself is prone to several inaccuracies and errors. These inaccuracies are not only attributed to the division of the dataset into test and training data (Chung and Fabbri 2003; Bell 2007; Kalantar et al. 2017), but also to the quality of the landslide inventory. The creation of the landslide inventory is usually the most time-consuming, subjective, and error-prone part in landslide susceptibility analysis (Carrara 1993; Mondini et al. 2014; Bell 2007; Galli et al. 2008; Guzzetti et al. 2000; Brardinoni et al. 2003; Petschko et al. 2014; Santangelo et al. 2015). Even though most recent studies performed a validation, the quality of the landslide inventory is often not scrutinized (Steger et al. 2017). However, validating susceptibility maps with an erroneous landslide inventory only gives information about the goodness of fit of a model, and results in misleading conclusions about the actual predictive power regarding future landslides. We, therefore, agree with Steger et al. (2016a, b, 2017) that high AUC values are necessary, but not sufficient to prove the ability of a model to predict landslide occurrence.

\section{Retrospective evaluation of landslide susceptibility maps}

Figure 6 presents the susceptibility maps of past statistical landslide investigations in the area around the two towns of Mössingen and Öschingen. The landslides caused by the heavy rainfalls in 2013 are marked in blue. The exact location of each susceptibility map in the study area is illustrated in Fig. 2. The following section analyzes the susceptibility maps with respect to the predictive power of the landslide events of 2013 and discusses causes for the differing results. It is important to note that the susceptibility maps are not based on the same susceptibility classes 


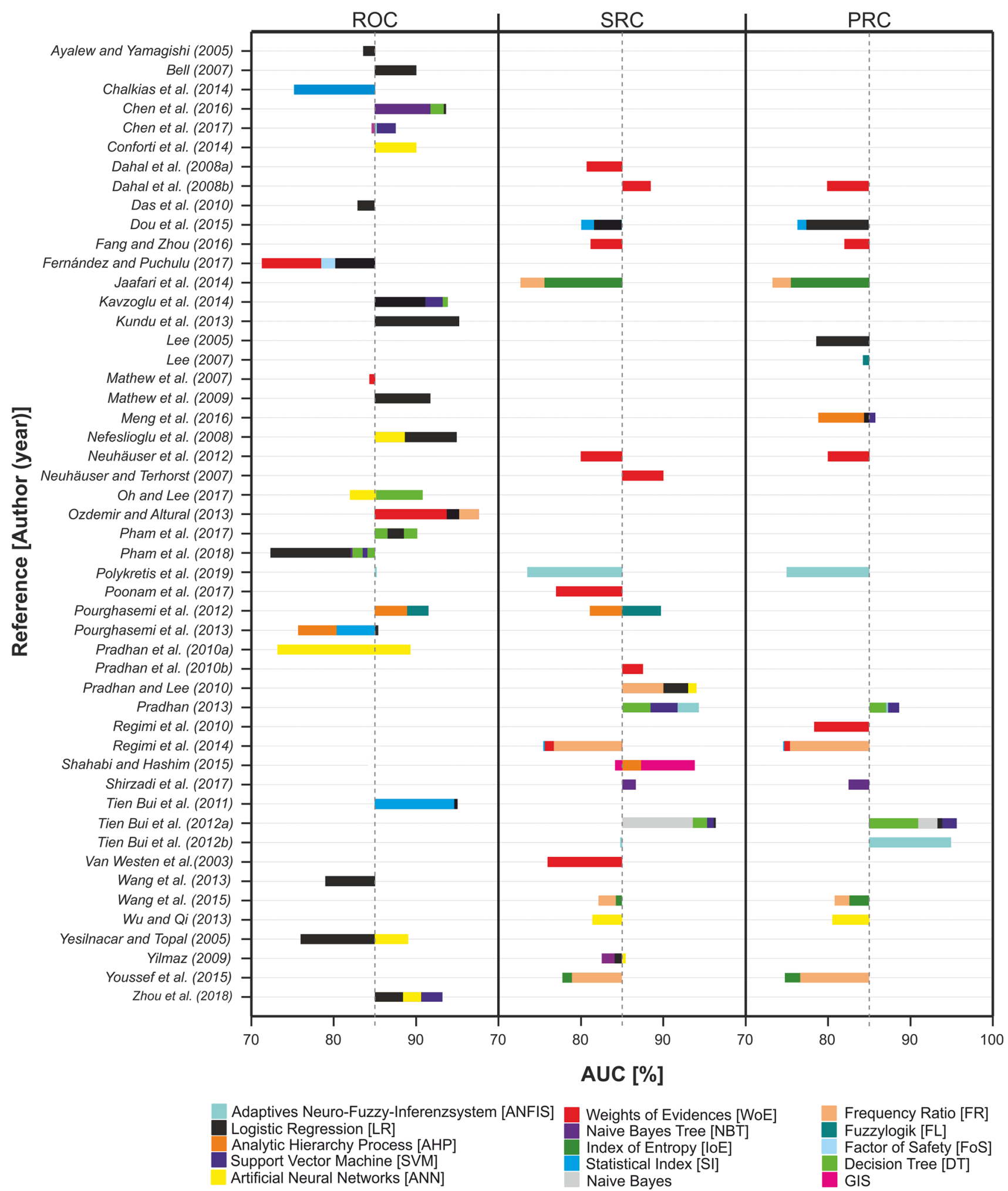

Fig. 5 Area under Curve (AUC) values of Receiver-Operating Characteristic (ROC) curves, Success Rate Curves (SRC), and Prediction Rate Curves (PRC) from 50 peer-reviewed, statistical landslide susceptibility analyses 
Fig. 6 Digitized susceptibility maps by a Bell (2007), b Neuhäuser and Terhorst (2007), c Thein (2000), and d Terhorst and Kreja (2009). Please note that the susceptibility classes of the original maps were not standardized. Landslides in the heavy-rainfall event in 2013 are marked in blue (a, $\mathbf{b}, \mathbf{c}$ : base map from Google Maps, 2017)
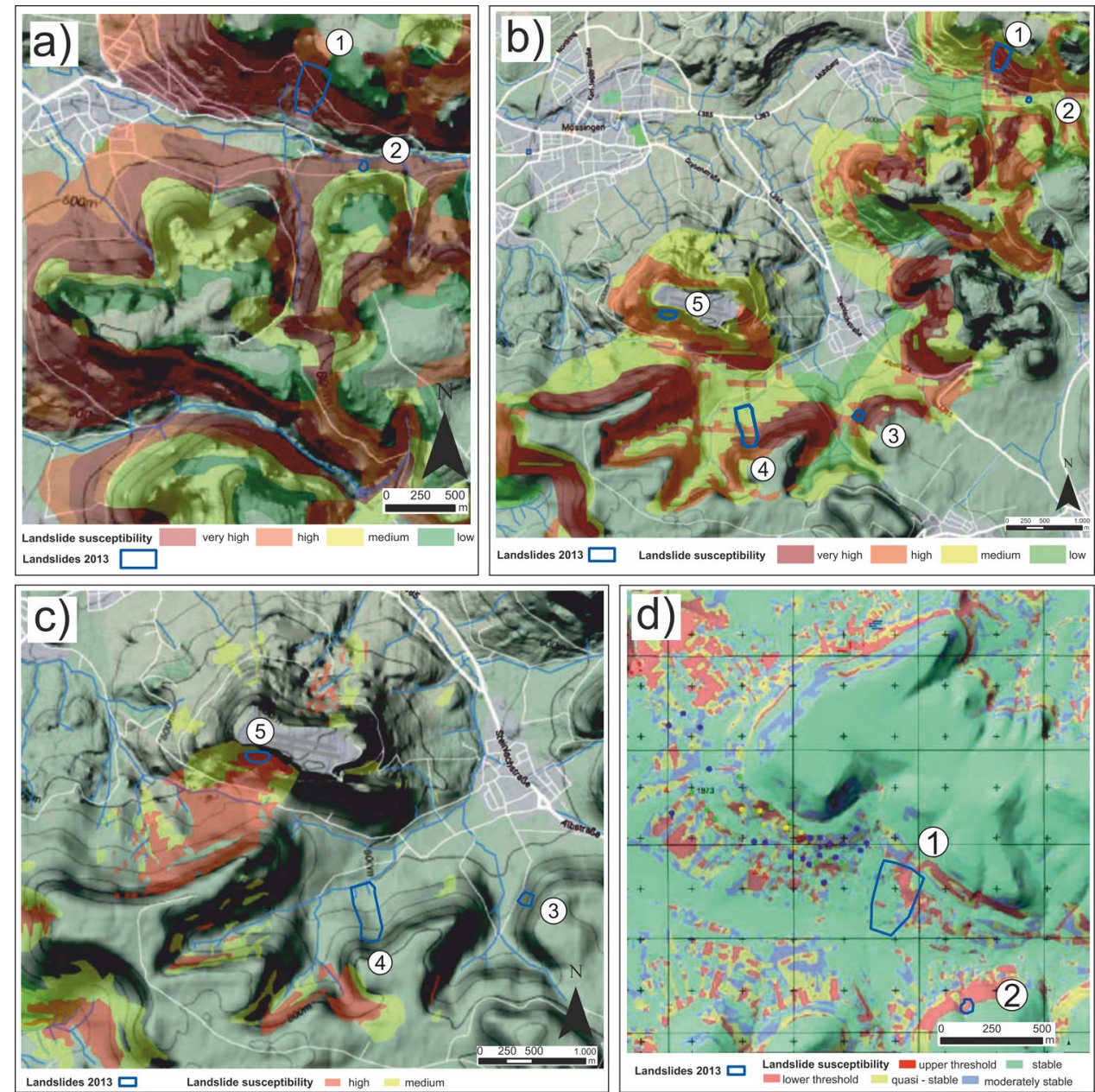

since the original classification ranks were not standardized. The analyzed maps also differ in terms of the size and resolution of the input data.

Bell (2007) calculated landslide susceptibility based on a logistic regression (LR) for the entire Swabian Alb (on a regional scale). Two of the landslides in 2013 are located within the map (Fig. 6a). Both landslides are located along slopes predicted as being highly susceptible to landslides. Compared to the other maps, however, nearly all semisteep slopes of the escarpment were classified as highly susceptible to landslides. This can be explained by the fact that the calculations are mainly based on geomorphological factors. Geological factors such as the lithology, which have a significant impact on landslide activity (Kraut 1999; Terhorst 1997; Thein 2000; Kallinich 1999), were not considered (Bell 2007; Terhorst and Kreja 2009). The susceptibility map provided by Bell (2007) was validated by ROC with an AUC between 85 and 98\%, which equals an excellent-outstanding predictive performance (Hosmer and Lemeshow 2000). However, considering the large study area, Bell's (2007) susceptibility map is more suitable for locating landslide-prone areas in the Swabian Alb than predicting single landslide events.

Neuhäuser and Terhorst (2007) used the method weights of evidence (WoE) to calculate landslide susceptibility for the Middle Swabian Alb on a regional scale. Five of the landslides in 2013 are located within the study area (Fig. 6b). Three of them are within the highest susceptibility classes, whereas two of the landslides are located along slopes that were classified by a medium susceptibility. Especially the devastating landslide at the "Öschinger Landhaussiedlung" (No. 1) was predicted very precisely. Compared to Bell (2007), one noticeable difference is the significantly smaller share of the highest susceptibility class. This can be explained by the smaller investigation scale and also by the integration of geological factors. The predictive performance is confirmed by an excellent validation score. The map was validated by the PRC and achieved an AUC value of $>90 \%$.

Thein (2000) investigated landslide susceptibility on a local scale using LR. In this study, three of the 2013 landslides are located in the map. The landslide on the south side of the Farrenberg (No. 5) was well predicted (Fig. 6c). 
In contrast, the model showed poor predictive performance for both landslides (No. 3, 4) in the south-eastern part of the study area. All slopes in this area were calculated as stable even though the largest landslide occurred here. It is also interesting that very flat areas with a slope angle below $5^{\circ}$ were classified as being highly prone to landslides. No validation was performed to verify the calculated susceptibility map. Of all maps analyzed, the study by Thein (2000) showed the lowest predictive accuracy. Residential area development planning based on this susceptibility map could have disastrous consequences. A qualitative assessment of the map would have also revealed that parts of the calculated probabilities are even geomorphologically implausible.

In contrast to the previously discussed studies, Terhorst and Kreja (2009) did not use a statistical, but a deterministic (infinite slope) approach based on hydrogeological and geomorphological data (Fig. 6d). Two of the landslides in 2013 are located within the study area. The occurrence of the small landslide (No. 2) in the south-eastern part of the study area was very well predicted by the model. This is also the case for the upper part of the landslide-affected area (main scarp and head) at the Öschingen residential area "Landhaussiedlung". However, the foot of the landslide body was labeled as stable. This can be explained by the applied model that mainly focuses on shallow and translational landslides. The susceptibility map was only validated in a qualitative way.

In summary, the largest landslide No. 1 was located in three of the four analyzed susceptibility maps and was classified in all of them as highly susceptible. The second landslide was also located in three study areas, but only two maps were able to predict it as highly susceptible. Landslides number 4 and 5 were located in two study areas each. However, only one map predicted them correctly. Thus, the analysis of past landslide susceptibility investigations in the area of Mössingen-Öschingen revealed significant differences in the predictive accuracy of the 2013 landslide events. This emphasizes the great importance of a sound validation, especially since only two of the four investigated studies validated their results. The discrepancies in predictive performance are not only attributed to different investigation scales, but also to the comprehensiveness and quality of the used input data.

\section{Discussion}

Our brief review of validation practice showed that virtually all published validations of landslide susceptibility maps reached high validation scores. In contrast, the retrospective validation presented in this study revealed significant discrepancies in the predictive accuracy of the four analyzed susceptibility maps with respect to the 2013 landslide event.
From this, we conclude that high validation scores are necessary, but not sufficient to validate the predictive power of such maps. Of course, a retrospective evaluation cannot be provided together with the (just) developed susceptibility map. In this case, scrutinizing maps by local site exploration and deterministic slope stability analysis at representative sites could minimize this limitation. However, in the cases where landslides occurred after the publication of a map, retrospective evaluation is clearly worth the effort to illustrate their validity and reliability (if the map was able to satisfactorily predict landslides) or improve them (if not).

Even though the retrospective analysis allowed us to draw key conclusions, it is important to consider this study as a demonstration. This mainly concerns the small size of the landslide inventory used for the retrospective evaluation, allowing only a qualitative evaluation instead of a statistically robust analysis of the susceptibility maps. This highlights the bottleneck of the retrospective evaluation, as this approach is dependent on the occurrence of a significant number of landslides within the investigation area after the creation of the original map. While susceptibility maps are usually created for areas with high landslide activity, an increasing number of such datasets will be available over time. To evaluate the predictive power also quantitatively, future studies should also consider utilizing the original data of the analyzed maps to reduce accuracy losses in the digitizing process.

Despite the demonstration character of this study, the retrospective validation approach turned out to be a promising assessment tool. While the burden to achieve a high validation score at least subconsciously influences the validation of a landslide prediction, the proposed approach allows an objective evaluation. In addition, in case of an imprecise or incomplete landslide inventory, susceptibility maps still achieve very high validation scores despite a low predictive performance. Retrospective evaluation allows a clear statement of the quality of the susceptibility map regardless of the quality of the original input data. This is particularly the case as recent landslide events can be mapped very precisely. Furthermore, most evaluations of susceptibility maps are of statistical nature. However, this approach enables the evaluation based on site-specific information. This "easy to see" approach is especially beneficial when dealing with authorities and landowners.

Landslides are a present and well-known hazard at the Swabian Alb. Apart from the fact that early warnings from the scientific community were not considered, the root cause of the problem is economically motivated development strategies of building areas along the semi-steep slopes of the Swabian Alb in the past (Kreja and Terhorst 2005; Sass et al. 2008). In some cases, approval of such building areas should not have been issued by the regulatory authorities. Nonetheless, early warnings by Neuhäuser and Terhorst (2007), 
Terhorst and Kreja (2009), and Bell (2007) received hardly any attention, neither by local nor by the state authorities. The case of Mössingen-Öschingen illustrates that effective landslide mitigation strategies require close cooperation between scientific and governmental institutions. Authorities should be more open to novel ideas and technologies, while scientists are obliged to take care of a comprehensible and sound susceptibility assessment. The differing susceptibility maps in the study area of Mössingen-Öschingen have certainly not promoted decisive actions from any decision makers.

Although not analyzed in the present study, the retrospective evaluation approach could also be a helpful tool in other natural risk assessment, such as floods, tsunamis, and wildfires. The only requirement is that a damage event occurred after publication of the susceptibility map.

\section{Conclusions}

Contrary to early statistical landslide investigations, the share of studies published together with a validation has been significantly increasing during recent years. However, several authors still validate their results without splitting the landslide inventory, and the impact of the landslide inventory on the predictive accuracy is hardly ever considered. High validation scores may disguise high uncertainties in landslide prediction. We, therefore, suggest to not only evaluate the predictive performance in a quantitative way by validation scores, but also in a qualitative way that scrutinizes results by a critical plausibility check.

Despite the great advantages of statistical methods, local authorities still mainly rely on deterministic or heuristic predictions. In the case of landslides in Mössingen-Öschingen, little attention was paid to warnings from statistical landslide susceptibility maps. One important step to build up trust in statistical methods is to present the resulting maps with annotations on how to interpret the results. It is not sufficient to justify the validity by a high validation score. In addition, a measure for the impact of each causative factor on calculated susceptibilities based on a sensitivity analysis would highly increase the transparency of landslide susceptibility maps.

Until now, little effort has been made to assess the prediction rate of past landslide susceptibility maps. The retrospective validation approach presented in this study revealed significant discrepancies in the predictive accuracy of the crucial 2013 landslide event in Mössingen-Öschingen. Both totally incorrect as well as very precise predictions were made in the previous studies. This quality assessment not only helps to reflect on the predictive performance of a susceptibility map, but also on the creditability of the validation. We are convinced that the proposed retrospective evaluation approach can help to increase the level of acceptance of statistical methods in the decision-making process of policy planers, as the reliability of such maps can be demonstrated in an objective and vivid manner.

Author contributions All the authors contributed to the study conception and design. Data collection and analysis were performed by Paul Fleuchaus. The first draft of the manuscript was written by Paul Fleuchaus, and all the authors commented on previous versions of the manuscript. All the authors read and approved the final manuscript.

Funding Open Access funding enabled and organized by Projekt DEAL.

Availability of data and material There are no linked research datasets for this submission. All data have been compiled from the cited references.

Code availability ESRI ArcGIS 10.0 was used for the analysis.

\section{Declarations}

Conflict of interest The authors declare that they have no conflict of interest/competing interests.

Open Access This article is licensed under a Creative Commons Attribution 4.0 International License, which permits use, sharing, adaptation, distribution and reproduction in any medium or format, as long as you give appropriate credit to the original author(s) and the source, provide a link to the Creative Commons licence, and indicate if changes were made. The images or other third party material in this article are included in the article's Creative Commons licence, unless indicated otherwise in a credit line to the material. If material is not included in the article's Creative Commons licence and your intended use is not permitted by statutory regulation or exceeds the permitted use, you will need to obtain permission directly from the copyright holder. To view a copy of this licence, visit http://creativecommons.org/licenses/by/4.0/.

\section{References}

Anderson MG, Holcombe E, Blake JR, Ghesquire F, Holm-Nielsen N, Fisseha T (2011) Reducing landslide risk in communities: evidence from the Eastern Caribbean. Appl Geogr 31:590-599. https://doi.org/10.1016/j.apgeog.2010.11.001

Awawdeh MM, ElMughrabi MA, Atallah MY (2018) Landslide susceptibility mapping using GIS and weighted overlay method: a case study from North Jordan. Environ Earth Sci 77:732. https:// doi.org/10.1007/s12665-018-7910-8

Ayalew L, Yamagishi H (2005) The application of GIS-based logistic regression for landslide susceptibility mapping in the KakudaYahiko Mountains, Central Japan. Geomorphology 65:15-31. https://doi.org/10.1016/j.geomorph.2004.06.010

Bell R (2007) Lokale und regionale Gefahren- und Risikoanalyse gravitativer Massenbewegungen an der Schwäbischen Alb. Dissertation, University of Bonn

Bibus E (ed) (1999) Vorzeitige, rezente und potentielle Massenbewegungen in SW-Deutschland: Synthese des Tübinger Beitrags zum MABIS-Projekt. In: Bibus E, Terhorst B (eds) Angewandte 
Studien zu Massenbewegungen Tübinger geowissenschaftliche Arbeiten D5, pp 1-58

Blöchl A, Braun B (2005) Economic assessment of landslide risks in the Swabian Alb, Germany research framework and first results of homeowners' and experts' surveys. Nat Hazards Earth Syst Sci 5:389-396. https://doi.org/10.5194/nhess-5-389-2005

Bousta M, Ait Brahim L (2018) Weights of evidence method for landslide susceptibility mapping in Tangier, Morocco. In: MATEC web of conferences 149, 02042. https://doi.org/10.1051/matec conf/201814902042

Brabb EE (1991) The world landslide problem. Episodes 14(1):52-61

Brardinoni F, Slaymaker O, Hassan MA (2003) Landslide inventory in a rugged forested watershed: a comparison between air-photo and field survey data. Geomorphology 54:179-196. https://doi. org/10.1016/S0169-555X(02)00355-0

Brenning A (2005) Spatial prediction models for landslide hazards: review, comparison and evaluation. Nat Hazards Earth Syst Sci 5:853-862. https://doi.org/10.5194/nhess-5853-2005

Carrara A (1993) Uncertainty in evaluating landslide hazard and risk. In: Nemec J, Nigg JM, Siccardi F (eds) Prediction and perception of natural hazards, proceedings symposium, 22-26 October 1990, Perugia, Italy. Springer Netherlands, Dordrecht, pp 101-109. https://doi.org/10.1007/978-94-015-8190-5

Chalkias C, Ferentinou M, Polykretis C (2014) GIS-based landslide susceptibility mapping on the Peloponnese Peninsula, Greece. Geosciences 4:176-190. https://doi.org/10.3390/geoscience s4030176

Chen W, Xie X, Peng J, Wang J, Duan Z, Hong H (2016) GIS-based landslide susceptibility modelling: a comparative assessment of kernel logistic regression, Naïve-Bayes tree, and alternating decision tree models. Geomat Nat Hazards Risk 8:950-973. https://doi.org/10.1080/19475705.2017.1289250

Chen W, Pourghasemi HR, Panahi M, Kornejady A, Wang J, Xie X, Cao S (2017) Spatial prediction of landslide susceptibility using an adaptive neuro-fuzzy inference system combined with frequency ratio, generalized additive model, and support vector machine techniques. Geomorphology 297:69-85. https://doi. org/10.1016/j.geomorph.2017.09.007

Chung CJF, Fabbri AG (2003) Validation of spatial prediction models for landslide hazard mapping. Nat Hazards 30:451-472. https://doi.org/10.1023/B:NHAZ.0000007172.62651.2b

Conforti M, Pascale S, Robustelli G, Sdao F (2014) Evaluation of prediction capability of the artificial neural networks for mapping landslide susceptibility in the Turbolo River catchment (northern Calabria, Italy). CATENA 113:236-250. https://doi. org/10.1016/j.catena.2013.08.006

Corominas J, van Westen C, Frattini P, Cascini L, Malet JP, Fotopoulou S, Catani F, van den Eeckhaut M, Mavrouli O, Agliardi F, Pitilakis K, Winter MG, Pastor M, Ferlisi S, Tofani V, Hervás J, Smith JT (2014) Recommendations for the quantitative analysis of landslide risk. Bull Eng Geol Environ 73:209-263. https://doi.org/10.1007/s10064-013-0538-8

Crozier MJ (2010) Deciphering the effect of climate change on landslide activity: a review. Geomorphology 124:260-267. https:// doi.org/10.1016/j.geomorph.2010.04.009

Dahal RK, Hasegawa S, Nonomura A, Yamanaka M, Masuda T, Nishino K (2008a) GIS-based weights-of-evidence modelling of rainfall-induced landslides in small catchments for landslide susceptibility mapping. Environ Geol 54:311-324. https://doi. org/10.1007/s00254-007-0818-3

Dahal RK, Hasegawa S, Nonomura A, Yamanaka M, Dhakal S, Paudyal P (2008b) Predictive modelling of rainfall-induced landslide hazard in the lesser Himalaya of Nepal based on weights-of-evidence. Geomorphology 102:496-510. https:// doi.org/10.1016/j.geomorph.2008.05.041
Das I, Sahoo S, van Westen C, Stein A, Hack R (2010) Landslide susceptibility assessment using logistic regression and its comparison with a rock mass classification system, along a road section in the northern Himalayas (India). Geomorphology 114:627-637. https://doi.org/10.1016/j.geomorph.2009.09.023

Dilley M, Chen RS, Deichmann U, Lerner-Lam AL, Arnold M (2005) Natural disaster hotspots: a global risk analysis. World Bank, Washington. http://hdl.handle.net/10986/7376. Accessed 23 October 2020

Dongus H (1977) Die Oberflächenformen der Schwäbischen Alb und ihres Vorlands. Kartenband. Marburger Geographische Schriften (72)

Dou J, Tien Bui D, Yunus AP, Jia K, Song X, Revhaug I, Xia H, Zhu Z (2015) Optimization of causative factors for landslide susceptibility evaluation using remote sensing and GIS data in parts of Niigata, Japan. PLoS ONE 10:e0133262. https://doi. org/10.1371/journal.pone.0133262

Eder W, Takara K, Wang F (2009) International cooperation initiatives. In: Sassa K, Canuti P (eds) Landslides-disaster risk reduction. Springer, Berlin, Heidelberg, pp 517-530

Etzelmüller B, Frauenfelder R (2009) Factors controlling the distribution of mountain permafrost in the northern hemisphere and their influence on sediment transfer. Arct Antarct Alp Res 41:48-58. https://doi.org/10.1657/1523-0430-41.1.48

Fang L, Zhou S (2016) Landslide susceptibility mapping in Longmen Shan Mountainous, East Himalaya with weight of evidence method. Int J Landslide Environ 4:1-8

Fernández DS, Puchulu ME (2017) Uncertainty and sensitivity analysis of GIS-based landslide susceptibility models in Northwestern Argentina. Implications for future hazard assessment at the basin scale. In: Rabassa J (ed) Advances in geomorphology and quaternary studies in Argentina: proceedings of the sixth Argentine geomorphology and quaternary studies congress. Springer International Publishing, Cham, pp 119-140. https://doi.org/10.1007/ 978-3-319-54371-0

Frattini P, Crosta G, Carrara A (2010) Techniques for evaluating the performance of landslide susceptibility models. Eng Geol 111:62-72. https://doi.org/10.1016/j.enggeo.2009.12.004

Galli M, Ardizzone F, Cardinali M, Guzzetti F, Reichenbach P (2008) Comparing landslide inventory maps. Geomorphology 94:268289. https://doi.org/10.1016/j.geomorph.2006.09.023

Glade T (2003) Landslide occurrence as a response to land use change: a review of evidence from New Zealand. CATENA 51:297-314. https://doi.org/10.1016/S0341-8162(02)00170-4

Gruber S, Haeberli W (2007) Permafrost in steep bedrock slopes and its temperature related destabilization following climate change. J Geophys Res 112:F02S18. https://doi.org/10.1029/2006JF0005 47

Guzzetti F (2006) Landslide hazard and risk assessment. Dissertation, University of Bonn

Guzzetti F, Carrara A, Cardinali M, Reichenbach P (1999) Landslide hazard evaluation: a review of current techniques and their application in a multi-scale study, Central Italy. Geomorphology 31:181-216. https://doi.org/10.1016/S0169-555X(99)00078-1

Guzzetti F, Cardinali M, Reichenbach P, Carrara A (2000) Comparing landslide maps: a case study in the Upper Tiber River Basin, Central Italy. Environ Manag 25:247-263. https://doi.org/10. 1007/s002679910020

Haque U, Blum P, da Silva PF et al (2016) Fatal landslides in Europe. Landslides 13:1545-1554. https://doi.org/10.1007/ s10346-016-0689-3

Hosmer DW, Lemeshow S (2000) Applied Logistic regression. John Wiley \& Sons Inc., Hoboken, NJ

Huppert HE, Sparks RSJ (2006) Extreme natural hazards: population growth, globalization and environmental change. Philos Trans 
Royal Soc A 364:1875-1888. https://doi.org/10.1098/rsta.2006. 1803

Jaafari A, Najafi A, Pourghasemi HR, Rezaeian J, Sattarian A (2014) GIS-based frequency ratio and index of entropy models for landslide susceptibility assessment in the Caspian forest, northern Iran. Int J Environ Sci Technol 11:909-926. https://doi.org/10. 1007/s13762-013-0464-0

Jakob M, Lambert S (2009) Climate change effects on landslides along the southwest coast of British Columbia. Geomorphology 107:275-284. https://doi.org/10.1016/j.geomorph.2008.12.009

Kalantar B, Pradhan B, Naghibi SA, Motevalli A, Mansor S (2017) Assessment of the effects of training data selection on the landslide susceptibility mapping: a comparison between support vector machine (SVM), logistic regression (LR) and artificial neural networks (ANN). Geomat Nat Hazards Risk 9:49-69. https://doi. org/10.1080/19475705.2017.1407368

Kallinich J (1999) Verbreitung, Alter und geomorphologische Ursachen von Massenverlagerungen an der Schwäbischen Alb auf der Grundlage von Detail- und Übersichtskartierungen. Tübinger Geowissenschaftliche Arbeiten D4:1-166

Kavzoglu T, Sahin EK, Colkesen I (2014) Landslide susceptibility mapping using GIS based multi-criteria decision analysis, support vector machines, and logistic regression. Landslides 11:425-439. https://doi.org/10.1007/s10346-013-0391-7

Klose M, Maurischat P, Damm B (2016) Landslide impacts in Germany: a historical and socioeconomic perspective. Landslides 13:183-199. https://doi.org/10.1007/s10346-015-0643-9

Kraut C (1999) Der Einfluss verschiedener Geofaktoren auf die Rutschempfindlichkeit an der Schichtstufe der Schwäbischen Alb. In: Tübinger Geowissenschaftliche Arbeiten (TGA) Reihe D5, pp 129-148

Kreja R, Terhorst B (2005) Naturgefahren in einem Baugebiet bei Öschingen an der Schwäbischen Alb: GIS-gestützte Ermittlung rutschungsgefährdeter Gebiete am Schönberger Kapf bei Öschingen (Schwäbische Alb). Erde 134:395-412

Kundu S, Saha AK, Sharma DC, Pant CC (2013) Remote sensing and GIS based landslide susceptibility assessment using binary logistic regression model: a case study in the Ganeshganga watershed, Himalayas. J Indian Soc Remote Sens 41:697-709. https://doi.org/10.1007/s12524-012-0255-y

Lee S (2005) Application of logistic regression model and its validation for landslide susceptibility mapping using GIS and remote sensing data. Int J Remote Sens 26:1477-1491. https://doi.org/ $10.1080 / 01431160412331331012$

Lee S (2007) Application and verification of fuzzy algebraic operators to landslide susceptibility mapping. Environ Geol 52:615623. https://doi.org/10.1007/s00254-006-0491-y

Lee CF, Huang WK, Chang YL, Chi SY, Liao WC (2018) Regional landslide susceptibility assessment using multi-stage remote sensing data along the coastal range highway in northeastern Taiwan. Geomorphology 300:113-127. https://doi.org/10. 1016/j.geomorph.2017.10.019

LGL (2014) Landesamt für Geoinformation und Landentwicklung: Mössingen-Talheim (Rutschung). https://fno-verfahren.lgl-bw. de/FISInternet/verfahren.xhtml?vfa=4045. Accessed 20 February 2019

Mathew J, Jha VK, Rawat GS (2007) Weights of evidence modelling for landslide hazard zonation mapping in part of Bhagirathi valley, Uttarakhand. Curr Sci 92:628-638

Mathew J, Jha VK, Rawat GS (2009) Landslide susceptibility zonation mapping and its validation in part of Garhwal Lesser Himalaya, India, using binary logistic regression analysis and receiver operating characteristic curve method. Landslides 6:17-26. https://doi.org/10.1007/s10346-008-0138-Z

Meng Q, Miao F, Zhen J, Wang X, Wang A, Peng Y, Fan Q (2016) GIS-based landslide susceptibility mapping with logistic regression, analytical hierarchy process, and combined fuzzy and support vector machine methods: A case study from Wolong Giant Panda Natural Reserve, China. Bull Eng Geol Environ 75:923-944. https://doi.org/10.1007/ s10064-015-0786-x

Mondini AC, Viero A, Cavalli M, Marchi L, Herrera G, Guzzetti F (2014) Comparison of event landslide inventories: the Pogliaschina catchment test case, Italy. Nat Hazards Earth Syst Sci 14:1749-1759. https://doi.org/10.5194/nhess-14-1749-2014

Nefeslioglu HA, Gokceoglu C, Sonmez H (2008) An assessment on the use of logistic regression and artificial neural networks with different sampling strategies for the preparation of landslide susceptibility maps. Eng Geol 97:171-191. https://doi.org/10. 1016/j.enggeo.2008.01.004

Neuhäuser B, Terhorst B (2007) Landslide susceptibility assessment using "weights-of-evidence" applied to a study area at the Jurassic escarpment (SW-Germany). Geomorphology 86:12-24. https://doi.org/10.1016/j.geomorph.2006.08.002

Neuhäuser B, Terhorst B (2009) Assessment of the landslide susceptibility at the Jurassic escarpment of the Swabian Alb by means of GIS-based statistical-probabilistic evaluation. Photogram Fernerkund Geoinf 2009(2):143-160. https://doi.org/10.1127/ 0935-1221/2009/0012

Neuhäuser B, Damm B, Terhorst B (2012) GIS-based assessment of landslide susceptibility on the base of the weights-of-evidence model. Landslides 9:511-528. https://doi.org/10.1007/ s10346-011-0305-5

Nsengiyumva JB, Luo G, Nahayo L, Huang X, Cai P (2018) Landslide susceptibility assessment using spatial multi-criteria evaluation model in Rwanda. Int J Environ Res Public Health 15(2):243. https://doi.org/10.3390/ijerph15020243

Oh HJ, Lee S (2017) Shallow landslide susceptibility modeling using the data mining models artificial neural network and boosted tree. Appl Sci 7:1000. https://doi.org/10.3390/app7101000

Ozdemir A, Altural T (2013) A comparative study of frequency ratio, weights of evidence and logistic regression methods for landslide susceptibility mapping: Sultan Mountains, SW Turkey. J Asian Earth Sci 64:180-197. https://doi.org/10.1016/j.jseaes.2012.12. 014

Petley DN (2010) On the impact of climate change and population growth on the occurrence of fatal landslides in South, East and SE Asia. Q J Eng Geol Hydrogeol 43:487-496. https://doi.org/ 10.1144/1470-9236/09-001

Petley D (2012) Global patterns of loss of life from landslides. Geology 40:927-930. https://doi.org/10.1130/G33217.1

Petley DN, Hearn GJ, Hart A, Rosser NJ, Dunning SA, Oven K, Mitchell WA (2007) Trends in landslide occurrence in Nepal. Nat Hazards 43:23-44. https://doi.org/10.1007/s11069-006-9100-3

Petschko H, Brenning A, Bell R, Goetz J, Glade T (2014) Assessing the quality of landslide susceptibility maps - case study Lower Austria. Nat Hazards Earth Syst Sci 14:95-98. https://doi.org/ 10.5194/nhess-14-95-2014

Pham BT, Tien Bui D, Prakash I (2017) Landslide susceptibility assessment using bagging ensemble based alternating decision trees, logistic regression and $\mathrm{J} 48$ decision trees methods: a comparative study. Geotech Geol Eng 35:2597-2611. https://doi.org/10.1007/ s10706-017-0264-2

Pham BT, Prakash I, Tien Bui D (2018) Spatial prediction of landslides using a hybrid machine learning approach based on random subspace and classification and regression trees. Geomorphology 303:256-270. https://doi.org/10.1016/j.geomorph.2017.12.008

Polykretis C, Chalkias C, Ferentinou M (2019) Adaptive neuro-fuzzy inference system (ANFIS) modeling for landslide susceptibility assessment in a Mediterranean hilly area. Bull Eng Geol Environ 78:1173-1187. https://doi.org/10.1007/s10064-017-1125-1 
Poonam RN, Champati Ray PK, Bisht P, Bagri DS, Wasson RJ, Sundriyal Y (2017) Identification of landslide-prone zones in the geomorphically and climatically sensitive Mandakini valley, (central Himalaya), for disaster governance using the weights of evidence method. Geomorphology 284:41-52. https://doi.org/ 10.1016/j.geomorph.2016.11.008

Pourghasemi HR, Pradhan B, Gokceoglu C (2012) Application of fuzzy logic and analytical hierarchy process (AHP) to landslide susceptibility mapping at Haraz watershed, Iran. Nat Hazards 63:965-996. https://doi.org/10.1007/s11069-012-0217-2

Pourghasemi HR, Moradi HR, Fatemi Aghda SM (2013) Landslide susceptibility mapping by binary logistic regression, analytical hierarchy process, and statistical index models and assessment of their performances. Nat Hazards 69:749-779. https://doi.org/ 10.1007/s11069013-0728-5

Pradhan B (2013) A comparative study on the predictive ability of the decision tree, support vector machine and neuro-fuzzy models in landslide susceptibility mapping using GIS. Comput Geosci 51:350-365. https://doi.org/10.1016/j.cageo.2012.08.023

Pradhan B, Lee S (2010) Landslide susceptibility assessment and factor effect analysis: Backpropagation artificial neural networks and their comparison with frequency ratio and bivariate logistic regression modelling. Environ Model Softw 25:747-759. https:// doi.org/10.1016/j.envsoft.2009.10.016

Pradhan B, Lee S, Buchroithner MF (2010a) A GIS-based backpropagation neural network model and its cross-application and validation for landslide susceptibility analyses. Comput Environ Urban Syst 34:216-235. https://doi.org/10.1016/j.compenvurb sys.2009.12.004

Pradhan B, Oh HJ, Buchroithner M (2010b) Weights-of-evidence model applied to landslide susceptibility mapping in a tropical hilly area. Geomatics, Nat Hazards Risk 1:199-223. https://doi. org/10.1080/19475705.2010.498151

Promper C, Puissant A, Malet JP, Glade T (2014) Analysis of land cover changes in the past and the future as contribution to landslide risk scenarios. Appl Geogr 53:11-19. https://doi.org/10. 1016/j.apgeog.2014.05.020

Regmi NR, Giardino JR, Vitek JD (2010) Modeling susceptibility to landslides using the weight of evidence approach: Western Colorado, USA. Geomorphology 115:172-187. https://doi.org/ 10.1016/j.geomorph.2009.10.002

Regmi AD, Devkota KC, Yoshida K, Pradhan B, Pourghasemi HR, Kumamoto T, Akgun A (2014) Application of frequency ratio, statistical index, and weights-of-evidence models and their comparison in landslide susceptibility mapping in Central Nepal Himalaya. Arab J Geosci 7:725-742. https://doi.org/10.1007/ s12517-012-0807-z

Reichenbach P, Rossi M, Malamud B, Mihir M, Guzzetti F (2018) A review of statistically-based landslide susceptibility models. Earth Sci Rev 180:60-91. https://doi.org/10.1016/j.earscirev. 2018.03.001

Rozos D, Bathrellos GD, Skillodimou HD (2011) Comparison of the implementation of rock engineering system and analytic hierarchy process methods, upon landslide susceptibility mapping, using GIS: a case study from the Eastern Achaia County of Peloponnesus, Greece. Environ Earth Sci 63:49-63. https://doi.org/ 10.1007/s12665-010-0687-z

Santangelo M, Marchesini I, Bucci F, Cardinali M, Fiorucci F, Guzzetti $F$ (2015) An approach to reduce mapping errors in the production of landslide inventory maps. Nat Hazards Earth Syst Sci 15:2111-2126. https://doi.org/10.5194/nhess-15-2111-2015

Sass O, Bell R, Glade T (2008) Comparison of GPR, 2D-resistivity and traditional techniques for the subsurface exploration of the Öschingen landslide, Swabian Alb (Germany). Geomorphology 93:89-103. https://doi.org/10.1016/j.geomorph.2006.12.019
Schädel K, Stober I (1988) Rezente Großrutschungen an der Schwäbischen Alb. Jahresh Geol Landesamtes Baden Württemberg 30:413-439

Shahabi H, Hashim M (2015) Landslide susceptibility mapping using GIS-based statistical models and Remote sensing data in tropical environment. Sci Rep 5:9899. https://doi.org/10.1038/srep09899

Shirzadi A, Bui DT, Pham BT, Solaimani K, Chapi K, Kavian A, Shahabi H, Revhaug I (2017) Shallow landslide susceptibility assessment using a novel hybrid intelligence approach. Environ Earth Sci 76:60. https://doi.org/10.1007/s12665-016-6374-y

Soeters R, van Westen CJ (1996) Slope instability recognition, analysis, and zonation. In: Turner AK, Schuster RL (eds) Landslides, investigation and mitigation. National Academy Press, Washington, pp 129-177

Steger S, Brenning A, Bell R, Glade T (2016a) The propagation of inventory-based positional errors into statistical landslide susceptibility models. Nat Hazards Earth Syst Sci 16:2729-2745. https://doi.org/10.5194/nhess-16-2729-2016

Steger S, Brenning A, Bell R, Petschko H, Glade T (2016b) Exploring discrepancies between quantitative validation results and the geomorphic plausibility of statistical landslide susceptibility maps. Geomorphology 262:8-23. https://doi.org/10.1016/j. geomorph.2016.03.015

Steger S, Brenning A, Bell R, Glade T (2017) The influence of systematically incomplete shallow landslide inventories on statistical susceptibility models and suggestions for improvements. Landslides 14:1767-1781. https://doi.org/10.1007/ s10346-017-0820-0

Tasoglu IK, Citiroglu HK, Mekik C (2016) GIS-based landslide susceptibility assessment: a case study in Kelemen Valley (YeniceKarabuk, NW Turkey). Environ Earth Sci 75:1291. https://doi. org/10.1007/s12665-016-6098-z

Terhorst B (1997) Formenschatz, Alter und Ursachenkomplexe von Massenverlagerungen an der schwäbischen Juraschichtstufe unter besonderer Berücksichtigung von Boden- und Deckschichtenentwicklung. Tübinger Geowissenschaftliche Arbeiten D2:1-212

Terhorst B (2001) Mass movements of various ages on the Swabian Jurassic escarpment: geomorphologic processes and their causes. Z Geomorphol 125:65-87

Terhorst B, Kreja R (2009) Slope stability modelling with SINMAP in a settlement area of the Swabian Alb. Landslides 6:309-319. https://doi.org/10.1007/s10346-009-0167-2

Thein S (2000) Massenverlagerungen an der Schwäbischen Alb - statistische Vorhersagemodelle und regionale Gefährdungskarten unter Anwendung eines Geographischen Informationssystems. Tübinger Geowissenschaftliche Arbeiten D6:1-187

Thiebes B (2011) Landslide analysis and early warning systems: local and regional case study in the Swabian Alb, Germany. Dissertation, University of Vienna

Tien Bui D, Lofman O, Revhaug I, Dick O (2011) Landslide susceptibility analysis in the Hoa Binh province of Vietnam using statistical index and logistic regression. Nat Hazards 59:1413-1444. https://doi.org/10.1007/s11069-011-9844-2

Tien Bui D, Pradhan B, Lofman O, Revhaug I (2012a) Landslide susceptibility assessment in Vietnam using support vector machines, decision tree, and naïve Bayes models. Math Prob Eng 2012:126. https://doi.org/10.1155/2012/974638

Tien Bui D, Pradhan B, Lofman O, Revhaug I, Dick OB (2012b) Landslide susceptibility mapping at Hoa Binh province (Vietnam) using an adaptive neuro-fuzzy inference system and GIS. Comput Geosci 45:199-211. https://doi.org/10.1016/j.cageo.2011.10.031

van Westen CJ, Rengers N, Soeters R (2003) Use of geomorphological information in indirect landslide susceptibility assessment. Nat Hazards 30:399-419. https://doi.org/10.1023/B:NHAZ.00000 07097.42735.9e 
Wang LJ, Sawada K, Moriguchi S (2013) Landslide susceptibility analysis with logistic regression model based on FCM sampling strategy. Comput Geosci 57:81-92. https://doi.org/10.1016/j. cageo.2013.04.006

Wang Q, Li W, Chen W, Bai H (2015) GIS-based assessment of landslide susceptibility using certainty factor and index of entropy models for the Qianyang County of Baoji city, China. J Earth Syst Sci 124:1399-1415. https://doi.org/10.1007/s12040-015-0624-3

Wu F, Qi S (eds) (2013) Global view of engineering geology and the environment. CRC Press, London

Yesilnacar E, Topal T (2005) Landslide susceptibility mapping: a comparison of logistic regression and neural networks methods in a medium scale study, Hendek region (Turkey). Eng Geol 79:251266. https://doi.org/10.1016/j.enggeo.2005.02.002

Yilmaz I (2009) Landslide susceptibility mapping using frequency ratio, logistic regression, artificial neural networks and their comparison: a case study from Kat landslides (Tokat, Turkey).
Comput Geosci 35:1125-1138. https://doi.org/10.1016/j.cageo. 2008.08.007

Youssef AM, Al-Kathery M, Pradhan B (2015) Landslide susceptibility mapping at Al-Hasher area, Jizan (Saudi Arabia) using GIS-based frequency ratio and index of entropy models. Geosci J 19:113-134. https://doi.org/10.1007/s12303-014-0032-8

Zhou C, Yin K, Cao Y, Ahmed B, Li Y, Catani F, Pourghasemi HR (2018) Landslide susceptibility modeling applying machine learning methods: a case study from Longju in the Three Gorges Reservoir area, China. Comput Geosci 112:23-37. https://doi. org/10.1016/j.cageo.2017.11.019

Publisher's Note Springer Nature remains neutral with regard to jurisdictional claims in published maps and institutional affiliations. 